\title{
Art and Meaning. Messiaen Influences on Romanian Composition Universes
}

\author{
CLAUDIA NEZELSCHI \\ "George Enescu" National University of Arts Iași \\ ROMANIA*
}

\begin{abstract}
In this paper, we will tackle several dominant Messiaen influences, as concerns ideas and/or technical approaches, on important Romanian composition systems, with reference to concepts such as musical character, number, Time/time, repetition. We will refer to characters as structures, characters as tuning systems and characters as musical/cultural paradigms as they occur in Aurel Stroe's creation, and then we will turn our attention to Ștefan Niculescu's melody-musical character with memory. Surprising but/and natural, objective but/and inspired, Niculescu opens up different perspectives on the personality of musical character as well. Numbers (what is fascinating is that they are mainly just figures) prove to be an example of simplicity as they comprise in a condensed manner technical information, emotions and musical inspiration. We will prove/illustrate this relying on three technical/semantic perspectives: poetry of numbers-duration in Liviu Glodeanu's creation, numbers defining dodecaphonic series cells in Roman Vlad's work, or numbers-foundation for the whole modal edifice in Vieru's perspective. As for time/Time, which is the main character of Messiaen's (and actually everyone's, even humanity's) musical, poetic, philosophical and theological thinking, we will only dwell on two hypostases, namely Stroe's and Niculescu's perspectives. Stroe conceives time as an element integrated in the sphere of memory and identity, as the recurrence in the present time of slices of memories involves the superposing of slices of time. For Niculescu, time is foundation, a condensation of the fact that syntax relies on two temporal categories, succesivity and simultaneity. We will dwell on the repetition "character" in the context of Aurel Stroe's mobiles, or in parts of monodies of periodicities, screens and loops in Anatol Vieru's creation. The conclusions will naturally follow the line of art and meaning.
\end{abstract}

Keywords: Messiaen, Stroe, musical character, number, paradox.

\section{Introduction}

Any heart-felt action of an individual is life enriching. The core of this action is the very source where art, meaning (and ultimately Logos), music draw their juice from and rise above a person's time-bound existence.

Due to his leaping/catastrophe/mutation/sublimation approaches, Olivier Messiaen is well known and has become synonymous of one of the common points for:

\footnotetext{
*apedemunte@yahoo.com
} 
- the map (of evolution/history) of composition technique,

- the map (of evolution/history) of ethos and reception, and of listening to music,

- the map of the cosmos of brain activity, considered here from the viewpoints of sharpness and synergy of senses, of assigning meaning to a stimulus, of generalization and, symmetrically, of plasticization, by transposing a nucleus of (abstract) information in concrete terms,

- the map (of evolution/history) of the man's power of communication on the vertical plane with the Heavens and the depths of the human soul, and on the horizontal plane with the fellowmen and with the Creation.

Post-Enescu Romanian composers (with a refined and rich cultural and composition universe, impregnated by essentially Romanian influences) guessed the technical and especially philosophical, existential (implicitly vital) thesaurus in Messiaen's universe and thus their creation also draws its energy from here, specifically integrated and sublimated, thus giving to the Messiaen core new meanings and new coherences.

\section{Musical Character}

Both art and meaning have chosen life as a limit/ideal, with its complexity, wonder, simplicity and harmony. Messiaen's as well as "our composers" composition idea of musical character goes along the same line (string).

Traité de rythme, de couleur et d'ornithologie, a diary of the synesthetic composer, also contains a vast counterpoint/accompaniment for the Turangalila symphony, by describing its mosaic of techniques and sources of motivation in poetic-compositional-mathematical terms. The core idea is that of musical character, in accordance with what the author called "sound flesh" (Messiaen, 1994-2002, p. 360), also known as figures-colors, timbres-durations. When referring to the Messiaen universe, Theodor Grigoriu described "characters acting on several superposed stages and a sequence of different actions taking place simultaneously" (Grigoriu, 1989). From the technical standpoint, in Messiaen's work, the melodic character is a section of a melody, a section that develops and evolves itself into a character, which is transposition: the multiple notes of each melody tackled as a series of melodic characters are divided into subsets-characters with their own transposition range, which remains constant in a sequence of transpositions/adaptations. The idea of sequencing is thus resumed in an evolved/refined/staggered form.

The procedure is thus fully illustrated in the second part of the symphony, Chant d'amour I/ mark 29, where the starting motive is divided in 4 subsets: A and B with 2 elements, $\mathrm{C}$ and $\mathrm{D}$ with one element. A and $\mathrm{C}$ will be constantly transposed with an ascending semitone, B will not be transposed, D will gradually go down by a semitone. 
The parallelism/analogy between the melodic and the rhythmic characters results from the fact that the individualization of a "character" is achieved by maintaining a direction of evolution: "the melodic character" is constantly transposed with the same range or distinguishes itself from the whole by maintaining a fixed pitch, "the rhythmic character" is constantly subjected to the same variation process or distinguishes itself from the whole by remaining constant. An example of rhythmic characters and an illustration of the analogy with melodic characters may be found in Part Three, Turangalîla I/9, where the percussion has three rhythmic characters:

$$
\begin{gathered}
\mathrm{R}_{1}=22 \\
\mathrm{R}_{2}=21112, \\
\mathrm{R}_{3}=77
\end{gathered}
$$

The first rhythm-character will be successively augmented, the second will remain unchanged, and the third will be successively diminished.

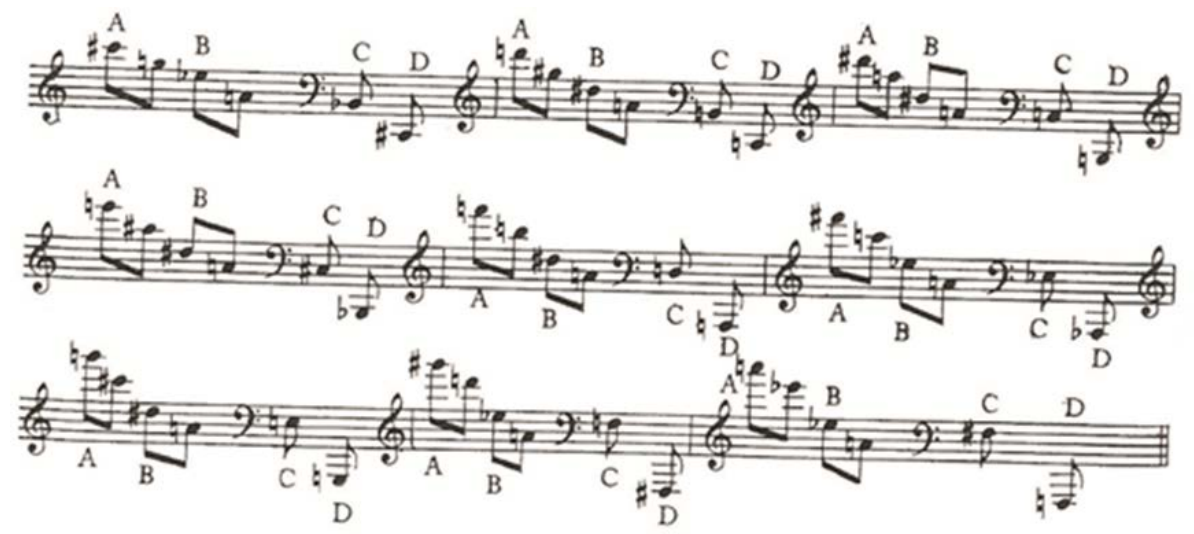

Fig. 1 Individualization of melodic characters by transposition

We further specify that the melodic/rhythmic parallelism extends, as Merssiaen brings the concept of chromaticity of duration, of rhythmic basic character in symphony dramaturgy, which consists of a sequence of consecutive numbers, in increasing or decreasing order (e.g. rhythm 456789 1011 is chromaticity of durations, marked $4-11$, its recurrence being also chromaticity of durations, chromaticity marked 11-4).

Messiaen will also create harmonic characters, sequences of chords that will be either repeated as a harmonic pedal, or transposed across sections, generating stratifications, fans.

By overlapping and specific processing, any sound structure may become a character in Messiaen's work. For example, in the fourth part of the symphony, Chant d'amour II/8, there are two overlapping trios: "two complete 
music evolving together, each with its own rhythm, melody, harmony, timbre" (Messiaen, 1994-2002, p. 221). In Chant d'amour II/14, we find that the scherzo theme is superimposed with other secondary constructions ("oiseaux" song, 3 rhythms, etc.). The two trios are also added to them, and Chant d'amour II/15 also includes the statue theme in trombone (thus reaching five musical layers).

The main idea that comes out is that, as in life, what defines the character (person) is its evolution, relation to time, and interaction with other similar structures (socialization, communion with peers).

Aurel Stroe, son of a physician, which made him even more familiar with the evolution (and pathology) of the living body, in the complex human context (the organic, vegetative aspect being in this case influenced/stimulated/staggered by mental, emotional, existential structures) achieved, in his composition process:

- characters as structures

- characters as tuning systems

- characters as musical/cultural paradigms.

When music reflects the relations, evolution/involution of certain structures comparable to characters, the result is morphogenetic music, as for instance Sonata I for piano, This will not win the Nobel Prize opera, Concerto for clarinet, Orestia I, II, III operas. Whereas sound discourse is built to highlight the compatibilities, incompatibilities, and especially the incommensurability of certain tuning systems, systems that may thus be seen as characters of becoming, confrontation or consensus, the result is the composition with several tuning systems, as for example the works Garden of Structures, Orestia II, Capricci and ragas, Ciaccona con alcune licenze. Whereas musical characters are sound figures-characters with a predominantly random "lifestyle", subjected to the moment and impulses, the result is represented by mobiles, a mobile being "a reservoir of very different sound figures that each musician executes in a free sequence" (Arzoiu, 2002)

In Ștefan Niculescu's work, the idea of musical character (an expression in line with the art and meaning perspective being the character/person in the life called music) may be conceived in the contexts of

- heterophony,

- timbre, timber/color being comparable to the personality/psyche of musical character.

In the case of heterophony, different hypostases-melodies of the main melody/model overlap, heterophony also serving the revelation of inner emotions, the dimensions of the concept of melody. Thus, it may be considered in this context that melody is a character with memory, as it includes polyphony/stratification of several psychological times, several mental/emotional realities, a common idea of many composers, including Messiaen and Stroe. 
Messiaen heard colors (just as, necessarily and naturally, many violonists/strings players hear and feel segments, as on the reception of a musical range, most often before becoming aware of it and before naming it, spatial and tactile sensations are activated on the string) so in the Traité de rythme, couleur et d'ornithologie, with the mathematical precision of poetic truth, the presence of energy-colors is described. Color sensitivity, timbrerelated preoccupations (necessary concerns, for example in its consistent rhythmic stratifications, as only the timbre of each layer allows the vital delimitation/clarification/separation/contouring), and treatment on musical characters may lead to the idea that timbre, and ultimately color, is the personality of the character.

By explaining and objectifying himself, Niculescu explains Messiaen, thus revealing deep, unifying aspects of disparities, even of opposites. The main ideas of Niculescu's plea-mathematical demonstration are:

$\circ$ color is intrinsic to reality, timbre is intrinsic to any sound manifestation;

$\circ$ totally different aspects of manifestation actually rely on the same principle, i.e. the vibration principle;

$\circ$ (musical) color is a determinant (and not a resulting) factor of music;

$\circ$ color and time cannot be separated, (the latter idea bringing a new motivation to Messiaen's preoccupation with time).

We reproduce Niculescu's ideas "Our consciousness senses the color of objects in a way similar to the sensing of the timbre of sounds, color seems to be a kind of garment for objects, just as timbre appears to be the cover of objects; objects cannot be seen in the absence of color (light), just as sounds cannot be heard in the absence of timbre; both colors and sounds are the result of vibrations [...], which are placed at different levels in the huge scale universal waves and which display the same absolute arithmetic continuity. [...] The quality of sound to which color-timbre relates depends on the complex synthesis of the other three qualities: pitch, intensity and duration [...]. Color and musical construction must be conceived simultaneously. If the range is the fundamental element of music, then this range must be a "total" range, i.e. the one separating pitches (of the fundamental and harmonics), intensities (of the fundamental and harmonics) and the duration of two sounds, and thus any timbres. Music must be constructed with such "total" ranges in which color penetrates as constituent element. If timbre is a function with several variables, including duration, then it is not possible to separate color from rhythm" (Niculescu, 1980, p. 256).

The idea of musical character thus gains consistency, this character having personality/timbre and life with rhythm in time.

Roman Vlad works with emblematic characters, musical cells comparable to mythical, biblical and archaic heroes, characters defined by 
precise, clear, integrative features in a multitude of contexts. An example is reverse chromaticism (often also present in Messiaen's work, both in his creations and in his theories of creation, and this from the very beginning in the Technique de mon langage musical), which is both mathematically precise and artistically inspired, and generates a dodecaphonic series defining a section of the Cantata for mixed choir and orchestra Le ciel est vide.

The series is:

$\mathrm{S}=$ (do\#, fa, ti flat, fa\#, do, re\#, ti, la flat, re, mi, la, so).

We will show that this series is deduced from the generating cell determined by a reverse chromaticism that is enharmonic with a diminished third with resolution. If the notes are assigned index numbers from the ascending order of the chromatic total, $\mathrm{S}$ becomes

$\begin{array}{llllllllllll}2 & 6 & 11 & 7 & 1 & 4 & 12 & 9 & 3 & 5 & 10 & 8 .\end{array}$

The differences between successive terms of this string of numbers are:

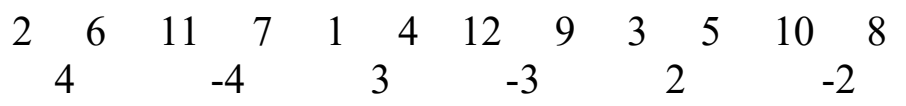

Considering the pairs of differences with the same module, namely (4, $4),(3,-3),(2,-2)$, there results a decomposition of the series of numbers into three groups, groups corresponding to 3 sets of notes:

$\begin{array}{llll}\text { do\# } & \text { fa } & \text { sib } & \text { fa\# } \\ \text { do } & \text { re\# } & \text { si } & \text { lab } \\ \text { re } & \text { mi } & \text { la } & \text { sol }\end{array}$

The columns in this matrix are variants, permutations of the generating cell transpositions determined by the first column. By marking the cell $3_{\text {do }}$ (do, do\#, re), it results that the $\mathrm{S}$ series is latent polyphony of the cells 3 do, 3 re\#, 3 la, $3_{\text {fatt. }}$ As one may notice, the "cellular" plan (paraphrase of the notion of modal plan) is determined by the arpeggio of the reduced seventh tuning do, re\#, fa\#, la.

This attempt to understand the compositional mechanism has given us the joy of discovering one of the hypostases of the elegance/beauty of mathematical thinking, the hyperlucidity enhanced by living semantic, emotional/status and communication needs. Vice versa, the apparent freedom or transience of musical discourse (willfully suggesting chaos reflecting the anxious quest for essentials) is actually generated by deep plans with full source-like clarity. Analogously, in life, what seems to be just about feeling, state or emotion is often deeply motivated and is related to psychoanalysis and precision of the unconscious, a veil of complete primordial and apparently impenetrable darkness, but having light/Light at its core, the root of vital, mental and emotional processes. Thus, this approach of Roman Vlad may be regarded as a reference for the unconscious of musical character, which, according to the suggestions above, as it proves to have personality, life rhythm and social (musical) interaction, is actually a musical person. 


\section{Number-composition character}

Life around us, which, although we do not always understand, we believe we know, is at the same time complex and organically varied (revealing, through its organization and coherence, the Creator's determinations, rhythm, thought and hand, and suggesting, when it exceeds our limitations, either infinity or chaos) and it is extremely precise, the number being one of its simplest landmarks. In a necessary and analogous, though seemingly paradoxical manner, we find the number as an amazing instrument in the composers concerned (and not only), a true composition character. Although "our" composers' musical ideas and emotional states have to do with abyss and the Infinity Heavens, the numbers used are generally figures, the operations with which are, in general, pedal repetition (prime numbers are mostly chosen for the length/mathematical cardinal of pedals; for pedal overlays it is often preferred that the pedal lengths be prime numbers between them), addition and subtraction to rhythmic transpositions and processes, permutation and, last but not least, elimination (elimination may also be considered a developmental technique, the essentialization intrinsic to elimination being development. We find this in concrete reality, especially in the context of spiritualization efforts).

The sharpness of perception, the character of motivations for composition struggles, the need of essentializing and reaching the big infinity through the small infinity of the revealing detail, brought Messiaen into tangency and dialogue with the Hindu universe. The Indian starts by breathing, taking heart beats as a unit of measurement. He reaches awareness and construction of rhythms as fine as filigree, the number actually being the pulse of order (initiatory order in most cases) in seemingly free and improvised music. Having its starting point in the heartbeat, the devoted Indian's rhythm opens to seemingly infinite yet overwhelming Time, time in quartet with Life, Death and God.

The number in rhythmic context leads to pedals in Messiaen's work, rhythmic characters with durations virtually close to the unimaginable in the context of measure, with limit evolutions in sensitivity and compositional/musical communication, evolutions consisting of

- augmentations

- diminutions

- stratifications / simultaneities of variants

- spaced out entries

- recurrences, concatenations, juxtapositions.

We notice that a symmetrical rhythm (juxtaposition of rhythm with its recurrence) advances and reinforces, along with the idea of development through elimination, the complementarity of opposites, the passage beyond linear binary thinking. 
From the intonation point of view, numbers reflect in the first stage how many semitones a range contains ${ }^{1}$, the spontaneity of the approach involving the range-number association, and ideas such as:

- the determination of 5 (the perfect ascending fourth)

- the sensitivity of 1 (minor second)

- the tension of 6 (augmented fourth)

- the dramatic nature of 11 (major seventh).

The approach proves, once again, the consubstantiality of music and mathematics, mathematical operations with numbers-ranges describing perfectly musical operations with ranges-numbers. Anatol Vieru, in his Book of Modes, utters in axiomatic style a theory of ranges and modes and reaches an exhaustive musical treatment by mathematical approach.

An example of unexpected efficiency through almost static compositional-mathematical gesture is Vieru's idea of monody of periodicities: each number is assigned a sound, the respective sound being present every time the corresponding number is involved. Vieru breaks down into primitive factors, assigns these prime factors to sounds, sounds that are present every time multiples of powers of the corresponding number come in.

\section{Time}

Time, seen through the magnifier of small infinity with the help of the rhythms defined by the poetry of numbers, is a theme/character at the heart of Messiaen's musical, poetical, philosophical and theological thinking. His creation contains:

- catastrophically long phrases ("hard" time, contemplation time, etc.),

- overlapping cosmos/chaos (precipitated time of questions, anxiety, the time of all consciousness),

- transformations of rhythm in which the identical-different distinction becomes problematic, and so on.

Aurel Stroe expressed his time-related ideas by referring in his creation:

- to time integrated in memory, identity

- to time reflected in the evolution/catastrophic evolution of a structure, morphogenetic music becoming a necessity.

In the sphere of memory there is the work entitled In our dreams we unravel overlapping times dwells on time-memory and superposes three layers of music, each layer corresponding to childhood memories: for clarinet, folklore heard in childhood and "transfigured by memories and dreams"

\footnotetext{
${ }^{1}$ Debutant guitar players naturally speak of $\mathrm{mi}_{11}, \mathrm{ti}_{5}, \mathrm{re}_{7}, \mathrm{la}_{4}$, most of them only contenting themselves with number references in a musical context and not using la $a_{4}=\mathrm{do \#}$ musical definition. Without suspecting it, they penetrate in the world of musical expressivity of numbers, as for them a song is a sequence of numbers.
} 
(Sandu-Dediu, 2002, p. 140), for piano, studies evoking Hanon's exercises, for cello, a childhood composition called Sunset. A general conclusion is that time in the context of memory makes it necessary for the presence of polyphony, of stratification, so that central techniques are also found in Messiaen's creation.

God is the end of Time. Thus, initially used in Stroe's work as background/framework for organic development, a development with inherent catastrophes that later reveal their role/effect of leaps/stages of evolution, the concept of time helps to coagulate some creations aimed at paradox, perception/thinking limit, controlled/liberating/clarifying/revelatory effect fight for Understanding, Truth, examples of such works being the Concerto for clarinet, and the Orestia I, II, III operas. Stroe also makes direct references to the revelatory dilemma, to the fight of the work of art and of the impossible symbolized/expressed by it with the listener's conscience, a fight that accounts for the ethos present in most of Stroe's creations. This fight is featured by Stroe, the proof being the choice of the motto to his paper defining and describing morphogenetic music: "our contemplation turns into a permanent struggle with Goya's paintings and with ourselves, because in the face of what we see we do not know what to think, if it is good or bad, if the significance is somehow or exactly the opposite" (Ortega y Gasset, 1972, p. 385).

As concerns time, Niculescu brings forward two essential concepts, with an exhaustive axiomatic character, namely simultaneity and successiveness. Successiveness features the triad rarefaction-detail-agglomeration, Messaien's long phrases illustrating the dyad detail-rarefaction, stratifications, the concept of agglomeration. Simultaneity has stratification as a major representative. Niculescu's heterophony is stratification of variants, variants that when arranged in succession, not simultaneously, would build Messiaen pedals, pedals with infinitesimal variations.

The dilatation of time, with a psychological effect of suspending it, also implies (and is involved by) the perception of the complexity of simplicity. The result is the contemplation of sound, sounds-long pedals (Messiaen's Quatuor pour la fin du Temps, Niculescu's Unisonos I, II) becoming the center of the inner space of music, a space that actually corresponds to the inner space of the listener, of the one becoming aware of it and of oneself.

This sound awareness corresponds to the description/rendering of things perceived/revealed, the "complexification of sound", the presence of blocks, of layers being often assimilated by both composers of a single sound/sound object.

In the sound-center register we find the idea of sound-foundation, of accompaniment. Comparable to essentialized melody, on necessary and sufficient sound, accompaniment is primarily a reference of the sound space determined by a melody. At the psycho-musical level, its seemingly steady 
state leaves room for the awareness of the dynamism of the inner universe, possibly of its tensions, dissonances.

\section{Repetition}

Accompaniment is a continuous perspective of the discrete contribution of repetition/pedal (terminology in mathematics, where the points in the set of natural numbers give the discrete appearance, and the points of the whole axis give the continuous appearance). Repetition, in line with the high/consistent quests of our composers, appears in many initiatory traditions as an effective multi-purpose tool. Taken by Messiaen (and not only by him) from nature (song of birds), it is present in his creation especially in the form of the pedal (rhythmic, melodic, harmonic). There are situations in which the progress in time of a pedal stratification of different lengths (generally prime numbers between themselves, in order to highlight all the combinations of simultaneities, each constituent being connected to all the constituents of the other pedals), although it consists of resumption/repetition and progresses semantically towards the full opening of consciousness to infinity both simple and complex, helps to increase the concrete, technically musical diversity. In the Turangalîla symphony, in Part One, Introduction/12, we find a 14-chord pedal built on a rhythmic pedal with 4 durations at the generator rhythm and a 13-chord pedal built on a rhythmic pedal with 6 durations in the generating rhythm. In Part Nine, Turangalîla III, there are 5 complex overlapping pedals, the number of chords and durations being shown in the table below.

\begin{tabular}{|c|c|}
\hline chords & durations \\
\hline 13 & 9 \\
10 & 2 \\
9 & 6 \\
14 & 9 \\
8 & 6 \\
\hline
\end{tabular}

Table 1 Messiaen, Turangalîla, Part Nine

The 5 overlapping harmonic pedals

Pause gains special importance and one may notice several of its hypostases. There are pauses interrupting rhythmical pedals, and where these pauses occur periodically, one may consider that a pedal of pauses is interjected.

In Aurel Stroe's creation, repetition occurs in the context of mobiles (for example, in the Concerto for Saxophone and Orchestra, "Prairie, prières", Part One, ...des formes naissent dans un milieu homogene, "Multimobile"), whereas Anatol Vieru expresses it by monodies of periodicity, screens, loops. We 
would also like to point out that the persistent repetition (mechanical or not) of a word, of an onomatopoeia occurs in everyday life in serious psychological/mental/relational situations, so that Aurel Stroe and Liviu Glodeanu employ such stratified pedals in Orestia and Zamolxis, respectively.

\section{Conclusions}

We tackled the concepts/categories of musical character, number, time/Time and repetition in the works of several composers, namely Olivier Messiaen, Aurel Stroe, Ștefan Niculescu, Anatol Vieru, Roman Vlad. Beyond them, at the base, though seemingly in the background, nonquantifiable/arguable, yet bringing about coherence and authenticity, one finds forceful ideas, ideas that motivate and define. Here are a few of the main ones, which are specific to all composers:

- the artistic effort, vertically searching for the Ultimate, expresses both the essence and the transient, the vulnerable, the harsh proximity;

- the paradox, sometimes the absurd or negation, are necessary elements for clarification, for limitlessness;

- emotion as the living source of (compositional) struggle, is expressed most effectively via hyperlucidity through structure.

Weather prone to artistic inclinations or not, every man sees, wonders, experiences inner struggles that seemingly/though invading his life, enrich it, make him feel alive and immortal. Through art, man's problems, their solution, the unspoken in him, find a possible (and, if inspired, successful) attempt to express themselves.

Life, the ultimate art, is what lies both bellow and above, being at the same time the core. Thus life itself is first and foremost in art and meaning: "So live life until you pass,/ All that suffering amass,/ And you'll hear the growing grass." (Eminescu, Vainly in those dusty classrooms)

Art and meaning, "and mystery its meaning half unveil" (Eminescu, The years have passed), in an ideal, inspired case, have their correspondence in the touch of sensitivity and complete communication/communion, essential knowledge/Logos whisper. Man, in addition to his mundane preoccupations (not random in essence), and due to his sensitivity, openness, on the one hand, and to his understanding, structuring, hyperlucidity, on the other, feels completely fulfilled in God: "I shall hear God's voice in me" (Psalm 84.8)

\section{References}

Arzoiu, R. (2002). Aurel Stroe-70 de ani [Aurel Stroe-70 years]. Muzica, 3, București. Eminescu, M. (2005). Poezii [Poems]. București: Editura EXIGENT. 
Grigoriu, Th. (1989). Olivier Messiaen la 80 de ani [Olivier Messiaen - 80 years]. Muzica, 3, 19-25.

Messiaen, O. (1994-2002). Traité de rythme, de couleur et d'ornithologie. Paris: Leduc.

Niculescu, Șt. (1980). Reflecții despre muzică [Reflections on music]. București: Editura Muzicală.

Ortega y Gasset, J. (1972). Velasquez, Goya. București: Editura Meridiane.

Sandu-Dediu, V. (2002). Muzica românească între 1944-2000 [Romanian music between 1944-2000]. București: Editura Muzicală.

Vieru, A. (1980). Cartea modurilor [The Book of Modes]. București: Editura Muzicală. 